ORNL/TM-11651

Office of Environmental and Health Protection

\title{
THE EFFECT OF VISIBLE LIGHT ON HARSHAW MODEL 8801 THERMOLUMINESCENT DOSIMETERS
}

\author{
E. Sonder \\ A. B. Ahmed \\ K. L. McMahan \\ D. S. Colwell \\ P. R. Smith \\ Date published - September 1990 \\ Prepared for office of Environment, \\ Safety, and Health \\ Prepared by \\ OAK RIDGE NATIONAL LABORATORY \\ Oak Ridge, Tennessee, 37831 \\ operated by \\ MARTIN MARIETTA ENERGY SYSTEMS, INC. \\ for the \\ U.S. DEPARTMENT OF ENERGY \\ under Contract No. DE-AC05-84DR21400
}




\section{CONTENTS}

Page

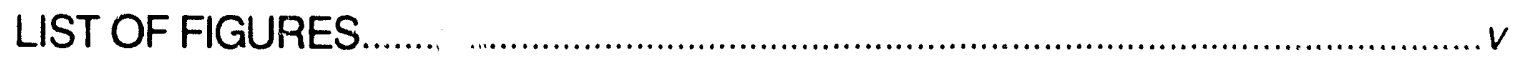

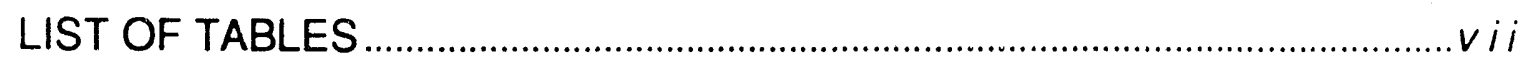

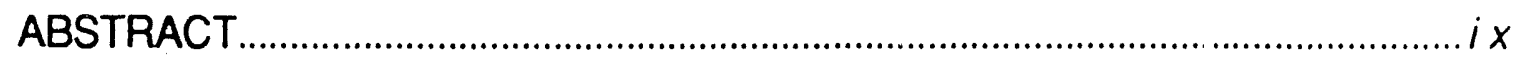

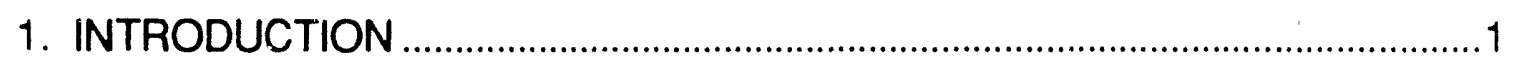

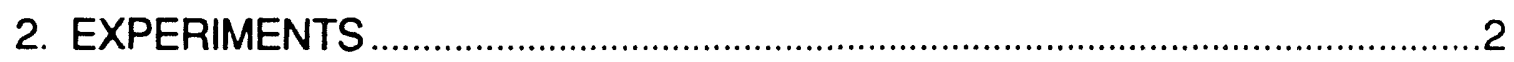

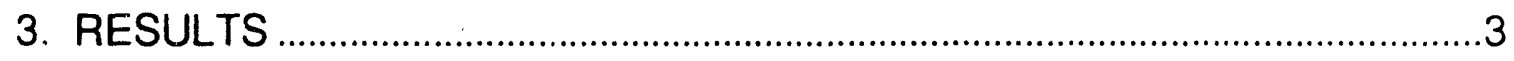

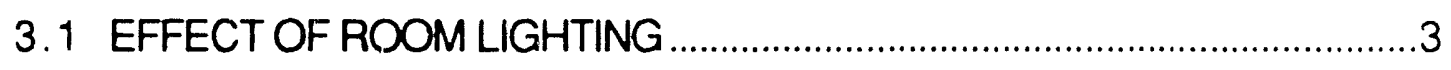

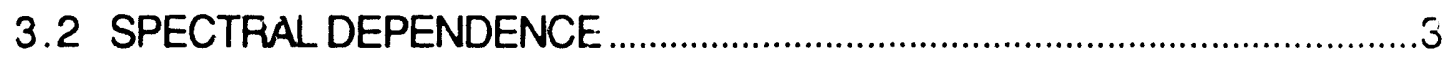

3.3 EFFECT OF SUNLIGHT ON DOSIMETERS INSIDE THEIR

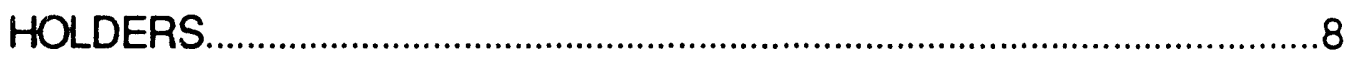

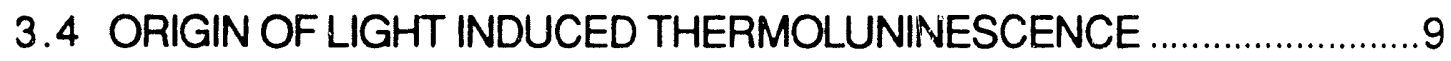

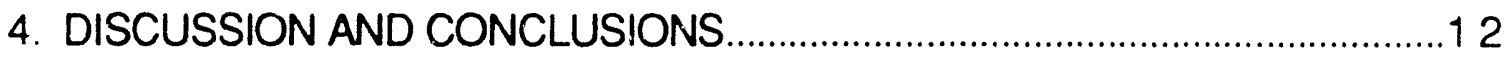

REFERENCES 


\section{LIST OF FIGURES}

Figure

Page

1 Increase of thermoluminescent response of Harshaw Lit dosimeter cards due to illumination with yellowtinted incandescent light. The response is given in pseudo-units of $\mathrm{mR}$ to allow comparison of the light response to the dosimeter's normal radiation response

2 Comparison of glow curves produced by light and by radiation. The ordinate scale is in arbitrary units:

(a) unirradiated, but illuminated, thin chip;

(b) irradiated, thin chip. 5

3 Fading of light induced thermoluminescence in Harshaw LiF dosimeter cards. The ordinate scale is in pseudo-units of $\mathrm{mR}$ as in Fig. 1; the abcissa is storage time in darkness after an initial illumination with incandescent light....

4 Spectral sensitivity of LiF dosimeter cards. Units for the ordinate scale are $\mathrm{mR}$ thermoluminescence response for dosimeter chip \#3 divided by light energy falling on the chip in joules

5 Comparison of glow curve produced by sunlight falling on an encapsulated dosimeter card with a glow curve produced by gamma rays. The ordinate scale is in arbitrary units 


\section{LIST OF TABLES}

Table

Page

1 Response of encapsulated dosimeter cards to sunlight.............8

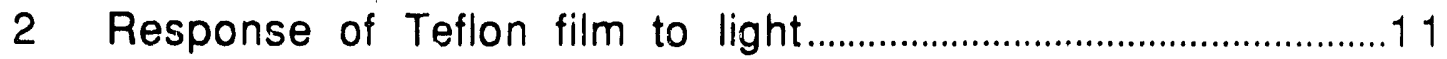




\begin{abstract}
It has been known for some time that illumination of lithium fluoride (LiF) thermoluminescent dosimeters, particularly with ultraviolet wavelengths, causes these dosimeters to emit thermoluminescence (TL), similar to that caused by exposure to radiation. However the effect of incandescent light on dosimeters is not ivell documented. In this study the growth, saturation and spectral dependence of this luminescence is studied for open dosimeter cards illuminated with room incandescent light, and for dosimeters inside their holders exposed to bright sunlight. The results confirm that illumination with room light does give rise to luminescence in unirradiated dosimeters. Light in the ultraviolet is an order of magnitude more efficient in producing this TL than is longer wave length (red) visible light. The illumination-induced TL saturates at intensities that correspond to TL produced by exposure of about $70 \mathrm{mR}$ of ${ }^{137} \mathrm{Cs}$; thus illumination clearly can give rise to false radiation exposure reports. Moreover it was found that the dosimeter holder allows enough sunlight to enter so that exposure of dosimeters to bright sunlight will activate some of the chips of the dosimeter cards in a fashion identical to that of room light. The glow curves produced by light are broader than those produced by gamma irradiation and a series of experiments have confirmed that the light induced TL comes from the Teflon sheets holding the LiF dosimeters, rather than the LiF chips themselves.
\end{abstract}




\section{INTRODUCTION}

One of the major sources of uncertainty in measurements of low radiation doses with LiF thermoluminescent dosimeters (TLDs) is the presence of backgrounc thermoluminescence (TL) in an annealed dosimeter (i.e., TL not due to previously absorbed ionizing radiation). It is known that ultraviolet light illumination can give rise to such background TL bands in TLDs ${ }^{1-3}$ or, conversely, can cause fading of radiation-produced bands 3 . We have recently observed that the magnitude of this background as well as the shape of TL glow curves can be changed significantly by illumination of the bare dosimeter cards with visible light. This phenomenon was discovered while reviewing glow curves of dosimeters exposed to TLD processing room lights even though these lights were expressly designed not to emit any ultraviolet radiation.

Another problem that has been appearing repeatedly in routine personnel monitoring may also be in part related to light illumination of dosimeters. This problem consists of unexplained and probably false high readings, usually together with anomalous glow curve shapes. Such readings most often appear in the \#3 chips (thin LiF for sensitivity to low energy beta and $X$ rays) of returned field dosimeters. These chips are covered with silvered mylar; however the silvering is not heavy enough to make the film completely opaque to light and it is not known whether enough light can enter a dosimeter to give rise to the occasionally observed anomalies.

The present study is airned at obtaining a better assessment of the effect of visible light on the TLD system ${ }^{4}$ in use at the Martin Marietta Energy Systems installations, with the expectation that such knowledge will allow us to better judge whether any modifications of procedure would increase the accuracy or reliability of our personnel dosimetry program. 


\section{EXPERIMENTS}

In most of the experiments described below TLD cards ${ }^{4}$ containing 4 LiF chips were used. There are two $0.015^{\prime \prime}$ thick (chips \#1 and 2) and one $0.0036^{\prime \prime}$ thick (chip \#3) TLD $700^{*}$ chips and one $0.015^{\prime \prime}$ thick TLD $600^{*}$ chip (chip \#4). Each chip is held between two Teflon sheets. The history of the dosimeter cards was not known in detail, but all of them had been irradiated to $500 \mathrm{mR}\left(5 \times 10^{-3} \mathrm{~Gy}\right)$ of ${ }^{137} \mathrm{Cs}$ gamma radiation for the development of element correction coefficients and then had had multiple further irradiations to low doses ( 5-20 mR) during their field use as personnel dosimeters. They were annealed at $300{ }^{\circ} \mathrm{C}$ after every irradiation, as part of the normal "read" cycles described below. Throughout this work we report the integrated TL outputs in pseudounits of $m R$, to allow easy comparison of the illumination effects with TL due to ionizing radiation, measured with the same equipment. During all the measurements reported below the samples received no significant ionizing radiation; only in samples stored for extended times for the purpose of measuring the stability of light induced TL was there any significant contribution of background radiation ( $\sim 1 \mathrm{mR} / \mathrm{week}$ ).

The reading/anneal cycle was the same as that used for routine personnel dosimetry, a linear temperature rise from $50^{\circ} \mathrm{C}$ to $300^{\circ} \mathrm{C}$ at a rate of $25^{\circ} \mathrm{C} / \mathrm{s}$, with a holding period at $300^{\circ} \mathrm{C}$ of $3.3 \mathrm{~s}$. The TL of the four chips was read simultaneously as a function of time (temparature) with an automatic dosimeter reading system. ${ }^{4}$ Room light illumination was performed with the dosimeter cards resting 12 " away from a yellow tirited incandescent tube light. 5 Monochromatic illumination was performed with a 100-watt tungsten lamp and a series of interference filters and lenses. The monochromatic light was focused so that only only one chip rather tha'l the whole card would be illuminated; even with the focusing $16 \mathrm{~h}$ of illumination was required to obtain observable changes. The intensity of light of the various wave lengths at the sample position was determined with a Si photo-diode, S 1337-66BQ.

"Harshaw Chemical Co. 


\section{RESULTS}

\subsection{EFFECT OF ROOM LIGHTING}

A dosimeter that has been annealed and kept in the dark will normally produce very slight residual signal during the reheating for another $\mathrm{Tl}$ acquisition run. This residual signal which includes the effect of noise in the photomultiplier corresponds to approximately 2. $\mathrm{mR}$ for the thick chips (numbers 1,2, and 4), and to $10 \mathrm{mR}$ for the thin chip (\#3). These values correspond to the detectability of the system. Upon illumination with visible light the subsequent signal during heating increases above this detectability limit. Fig. 1 depicts the integrated intensity of the TL for thin and thick chips as a function of illumination time. It is clear that the light induced luminescence is significant, particularly for the thin chip. The light induced TL begiris to saturate after approximately 10 hours at values of $\sim 60 \mathrm{mR}$ (thin chip) and $\sim 15 \mathrm{mR}$ (thick chips). Although not shown in Fig. 1, illumination for much longer times (150 hours) causes the light induced TL to increase only a slight amount, to $70 \mathrm{mR}$ and 17 $\mathrm{mR}$ respectively.

The shape of the TL glow curve is rather broad and peaks at a lower temperature than that produced by ionizing radiation. This fact can be seen clearly in Fig. 2 where typical glow curves for illuminated and irradiated samples are depicted.

The fading behavior of the light induced TL is shown in Fig. 3. About half of the stored luminescence disappears upon storage in the dark for 3-5 days. It is not possible to determine a more accurate value of the "half life" because the dosimeters vary in their TL output near their detectability limit.

\subsection{SPECTRAL DEPENDENCE}

The spectral dependence of the light induced TL is shown in Fig. 4. In that figure the sensitivity

$$
S=(D-D o) / / t
$$

where $D$ is the integrated TL ouiput $(m R), D o$ is the residual signal for an annealed chip, $I$ is the light intensity in watts, and $t$ is the illumination time plotted as che ordinate. The wave length of the 


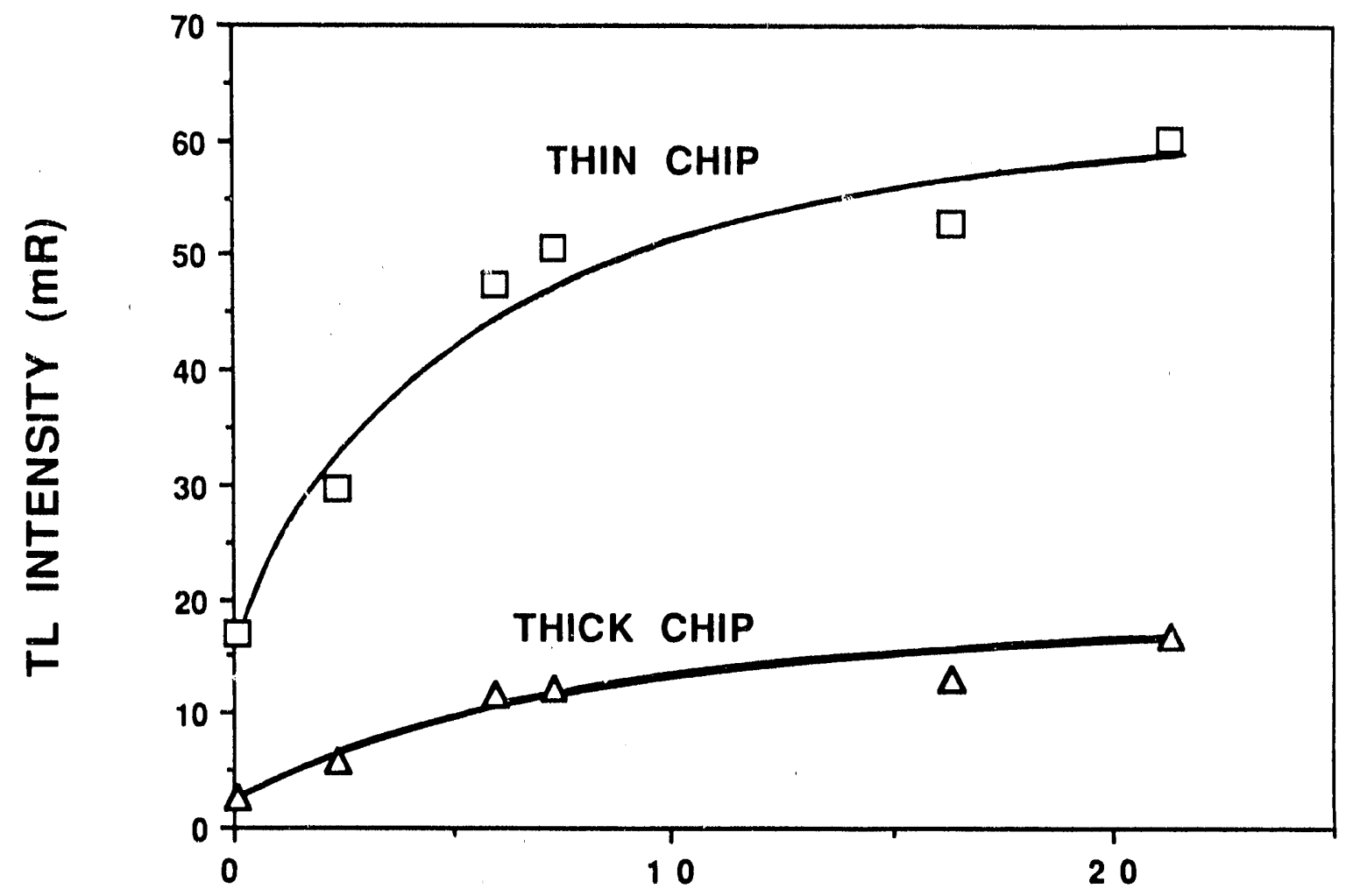

TIME (h)

Fig. 1. Increase of thermoluminescent response of Harshaw LiF dosimeter cards due to illumination with yellow tinted incandescent light. The response is given in pseuo-units of $\mathrm{mR}$ to allow comparison of the light response to the dosimeter's normal radiation response. 


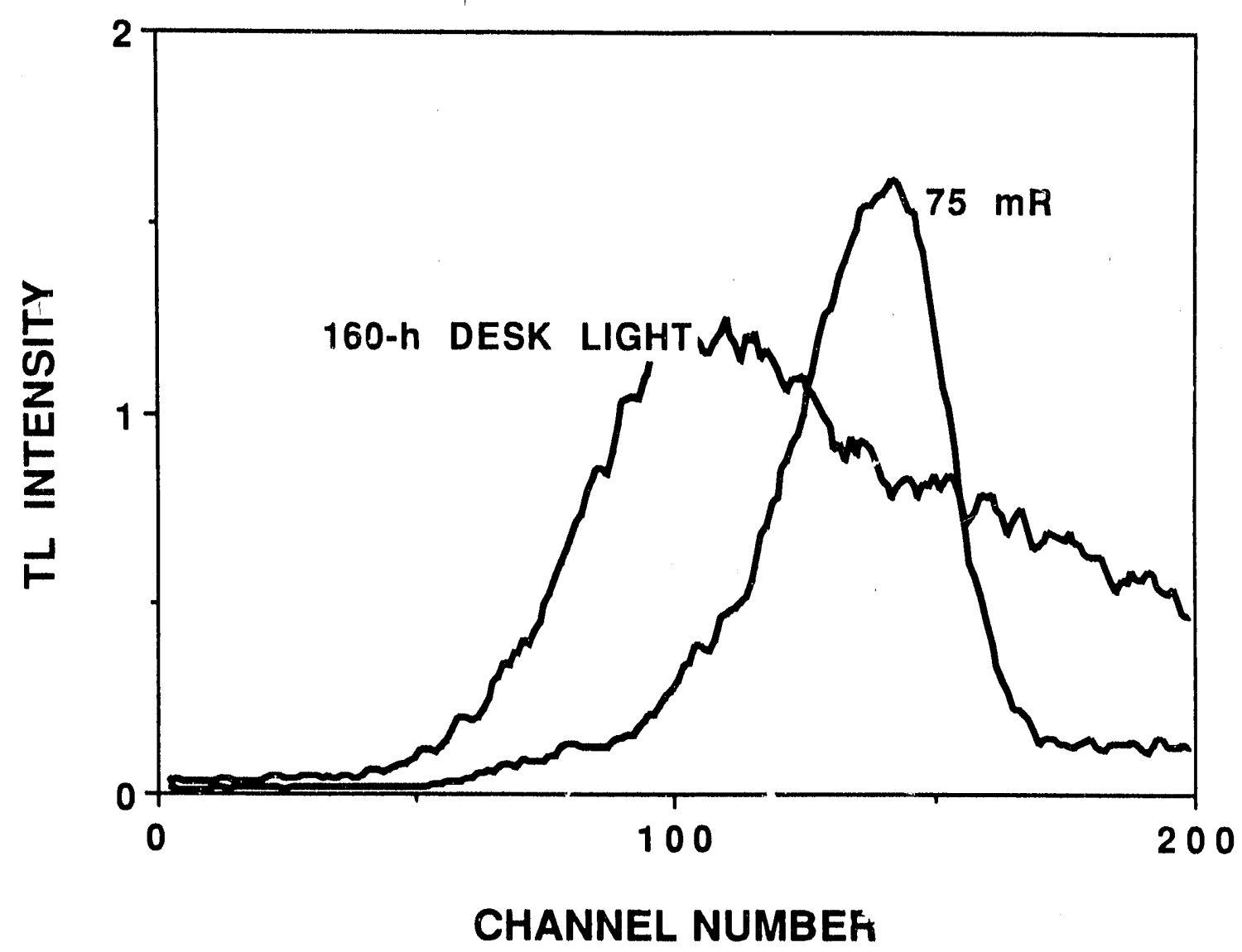

Fig. 2. Comparison of glow curves produced by light and by radiation. The ordinate scale is in arbitrary units. 


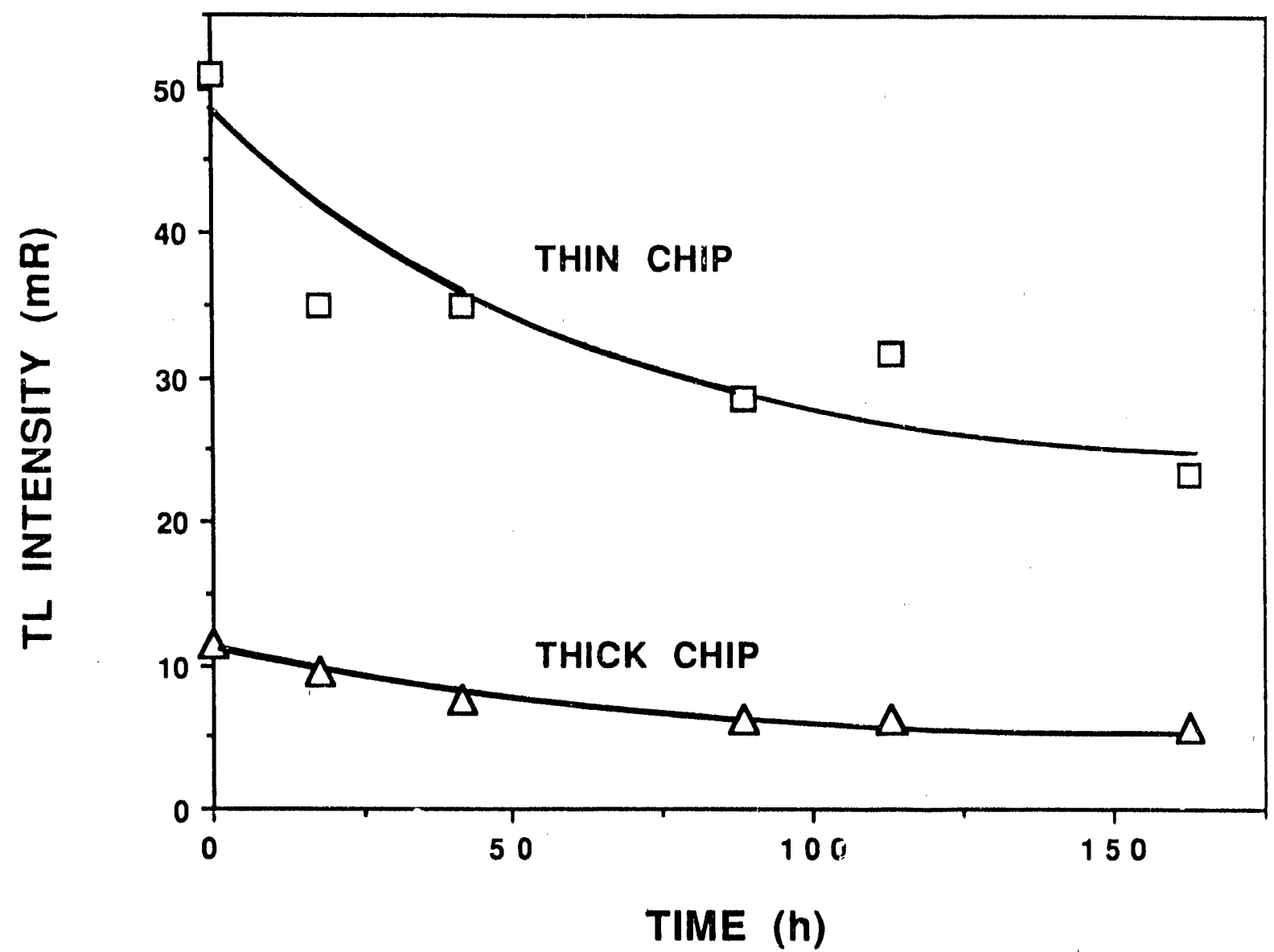

Fig. 3. Fading of light induced thermoluminescence in Harshaw LiF dosimeter cards. The ordinate scale is in pseudo-units of $\mathrm{mR}$ as in Fig. 1; the abcissa is storage time in darkness after an initial illumination with incandescent light. 


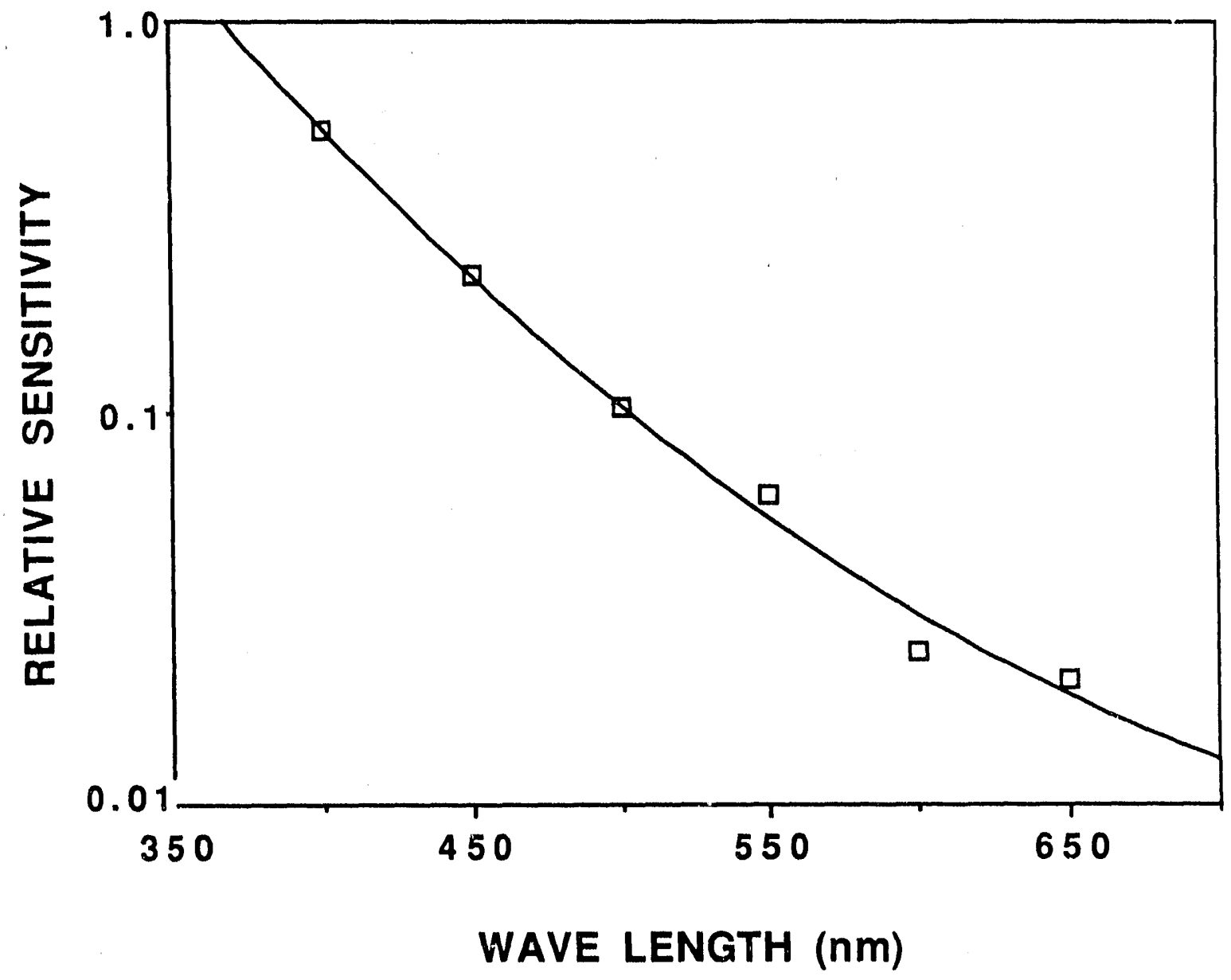

Fig. 4. Spectral sensitivity of LiF dosimeter cards. Units for the ordinate scale are $m R$ thermoluminescence response for dosimeter chip \#3 divided by light energy falling on the chip in joules. 
llighth is phlotted as: the abcissa. It is clear from the figure that ulitiraviolet lighth is arr order of magmitude more etficient in producing the $T L$ uinder diliscussion, butt that eveni red lighth cam produce a sigmifficamt effect. There is no evidence of any stharp structure in the specturall dependence of the illlumimation sensitivitity.

\subsection{EFFECT OF SUNLIGHT ON DOSIMETERS INSHDE THEIR HOLDERS}

The above described resull's sthow cleamiy that wisiblle lighthit produces. a TL respomse im LiF dosiimneter ciards. Morreoven, we know that the dosilmeter fromits used at Martim Mariietta Energy Systems are mot complletelly lighthit tigght; mot totallly opaque and a simalll amoumit of addilitionall light enters att the slot used to imsent identifying labells. The average $T L$ measured omi 2 sets of 5 encapsullatted dosimeters, exposed, respectivelly, 4 th and $61 / / 2$ th to brightht sumllighthit is compared in Tablle 1 with identicall dosilmeters kept im the dark. Cllearly chilip 3 exhibits TL comparabile to the saturation levell dettermimed with room lightht; chips til and 4 aliso: sthow sigmifficamit imcreases im TL. Chips til and are localled, whem encapsullated, mear the " $T$ " silot thirough which the labell passes and thiroughth which lighth can enter tithe dosimmeter.

Table 1. Response of encapsulated dosimeter cards to sunlight

\begin{tabular}{|c|c|c|c|c|}
\hline \multirow[b]{2}{*}{ Treattment } & \multicolumn{4}{|c|}{ Dosimeter chilp nuimiber } \\
\hline & ii & $i i i$ & iilii & iiv \\
\hline No llight & 11.87 & 2.47 & 13.8 & 1.68 \\
\hline 4 his sumlingthit & 695 & 4.39 & 49.0 & 6.94 \\
\hline 6.5 th surinlighth & 7.50 & 3.70 & 533 & 6.28 \\
\hline $\begin{array}{l}6.5 \mathrm{~h} \text { sumilighth } \\
\text { and } 7 \mathrm{~d} \text { im darth }\end{array}$ & 4.93 & 3.30 & 391.7 & 5.50 \\
\hline
\end{tabular}


Fig. 5 depicts a typical glow curve from chip \#3 of one of the sunlight illuminated dosimeter bards. The curve is compared with one produced by gamma irradiation. The difference in curve shape supports the proposition that sunlight illumination of encapsulated dosimeters has a similar effect às does visible room light illumination.

\subsection{ORIGIN OF LIGHT INDUCE THERMOLUMINESCENCE}

As indicated in Section 31 , the ight induced $T L$, when expressed in $\mathrm{mR}$ equivalent units, is greater by a factor of three in the thin $\# 3$ chips than in the thick chibs. If this TL were due to electron; trapped throughout the butlk of the LiF chip (similar to the effect of ionizing radiation) then the thin and thick chips would yield a more comparable $\mathrm{mR}$ equivalent TL output. On the other hand, the surface to volume ratio is greater for the thin chips, so that TI stemming from surfaces would be greater trom this thin chip. Also the LiF crips in the dosimeter cards are covered with Teflon sheets; the relative amount of Teflon is aiso greater for the thin chips. Masone has postulated that light induced TL comes from Lif surfaces; Hoots \& Landrum ${ }^{1}$ mention that plastic can contribute to the TL. Also Horowitz ${ }^{7}$ and Spanne ${ }^{8}$ refer to earlier mo: ${ }^{\prime} \bar{y}$ that indicates that adhesive covered Teflon tape gives rise t.ง TL glow peaks with maxima at approximately $120^{\circ} \mathrm{C}$. In order to determine whether the light induced $\mathrm{TL}$ we observe stems from the chip surface or the Tefion sheets that hold the chips in the dosimeter cards, we removed the LiF chips from a number of dosimeter cards and illuminated and measured the induced TL of these cards. In Table 2 we show the average TL response of three cards without LiF, after a three day illumination visible (yellow) light and after three cays in the dark. These data are compared with the response of normal dosimeter card's. Clearly the $T L$ response of the cards without LiF is greater than that of dosimeters that contain LiF chips. The fact that the response of the Lif-free cards is greater rather than equal to that of normal cards can be explained by that fact that the LiF chips shield a portion of the Teflon sheets from the ligint. 


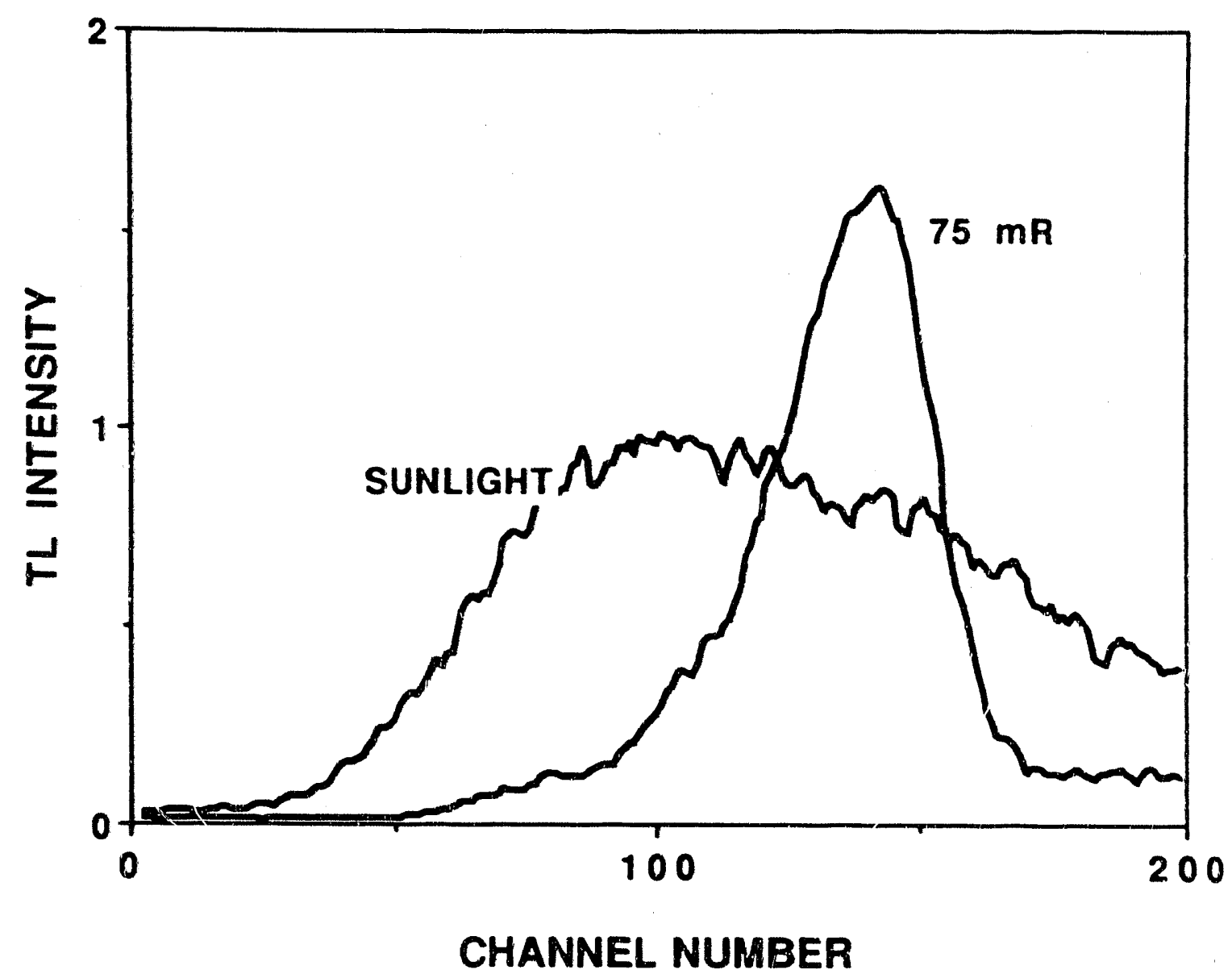

Fig. 5. Comparison of glow curve produced by sunlight falling on an encapsulated dosimeter card with a glow curve produced by gamma rays. The ordinate scale is in arbitrary units. 
Table 2. Response of Teflon film to light

Treatment of dosimeter card Dosimeter chip position

$i \mathrm{ii} \quad \mathrm{iii}_{\mathrm{i}}$

Annealed

4.64

4.02

20.9

4.50

Annealed and

$3 d$ in dark

4.30

4.01

19.9

3.61

Annealed and

illuminated $3 \mathrm{~d}$

26.6

26.5

117.4

27.1

with yellow light

Normal dosimeter card for comparison

Card with LiF chip

3 d illuminated

17 (thick chip)

70 (thin chip) 


\section{DISCUSSION AND CONCLUSIONS}

The experiments described above have shown that exposure of Harshaw 8801 TLD cards to room light can produce a TL response. This response corresponds to signals from exposure of $\sim 70 \mathrm{mR}$ of ${ }_{137} \mathrm{Cs}$ gamma radiation on chip \#3 and $\sim 17 \mathrm{mR}$ on the thicker chips. Since the lower limit of reporting radiation exposure is $10 \mathrm{mrem}$ for chip 1 (deep dose-equivalent) and $30 \mathrm{mrem}$ for chip 3 (shallow doseequivalent), the light induced TL can give rise to false positives if some precautions are not taken. The simplest precaution is to limit the light exposure of dosimeter cards after they have been removed from their holders. Fig. 1 indicates that $12^{\prime \prime}$ away from a yellow incandescent light $\sim 1 \mathrm{~h}$ of illumination produces about $1 / 10$ of the saturation TL. Thus if yellow tinted incandescent light is used in the processing room and exposure of the dosimeter cards to light is limited to a few minutes, the illumination effects should be negligible. Nevertheless procedures should be modified to indicate that whenever dosimeter cards are left unattended, they should be covered.

Blue to ultraviolet light is more efficient than yellow light in producing the TL under discussion. Bright sunlight on encapsulated dosimeters can cause a problem. To eliminate this effect requires heavier silvering or darkening of the mylar film and redesign of the dosimeter front to eliminate or at least decrease the light transmission of the label insertion slot.

Since the light induced luminescence stems primarily from the Teflon sheets holding the LiF chips, development of a less light sensitive plastic or other encapsulation material may eliminate the problem under discussion.

A recent study was made of the light sensitivity of LiF-Teflon thinsheet beta dosimeters. 10 The author(s) found, as we did, significan' thermoluminescence after exposure to light. Although they report a more complex spectral response than we found, it is probable that much of the effect they have observed is due to the Teflon binder used in these dosimeters.

The data presented above are for unirradiated dosimeter cards. Supporting our findings is a very recent study by Bradley ${ }^{11}$ of the combined effect of radiation and fluorescent light illumination on 
similar dosimeters. The author found that illumination of unirradiated dosimeters produced, respectively, $\sim 20$ and $\sim 70 \mathrm{mR}$ equivalent $T L$ in thick and thin unirradiated chips. This result is in agreement with our findings. Moreover Bradley 11 found that for combined irradiation and illumination the effect of illumination lessened as the irradiation increased; at doses > $500 \mathrm{mR}$ (0.5 Gy) subsequent illumination actually tended to produce fading, in agreement with previous studies. ${ }^{3}$

There has been some discussion in the literature 12,13 of the phenomenon of photo-transferred thermoluminescence (PTTL), in which heavily irradiated and annealed samples can be reread after illumination with ultraviolet. For some materials, $\mathrm{LiF}: \mathrm{Mg}, \mathrm{Ti}$ among them, the first readout anneal does not remove all radiation induced trapped charges. Deeply trapped charges are not removed by a $300^{\circ} \mathrm{C}$ anneal and can be redistributed by light $S D$ that a subsequent readout anneal will produce thermoluminescence, of the order of a few percent of the original readout. It should be pointed out that the samples used for the present experiments had not been heavily irradiated. The largest dose was that due to the original calibration $(500 \mathrm{mR})$, after which multiple anneals occurred. We estimate from the PTTL studies in the literature 12,13 that previous irradiation up to $1 \mathrm{R}$ followed by anneals would produce PTTL no greater than $3 \mathrm{mR}$ and therefore would not be the source of the effects we attribute to illumination. 


\section{REFERENCES}

1. S. Hoots, and V. Landrum, "Glow Curve Analysis for Verification of Dose in LiF Chips," Health Physics 43, 905 (1982).

2. L Musilek and K. Petrova, "Some Aspects of Use of Thermoluminescence Glow Curves," Kernenergie 30, 183 (1987).

3. J. W. N. Tuyn, and A. R. Lakshmanan, "Light Sensitivity of Some Common Thermoluminescence Dosimetry Phosphors," Radiation Protection Dosimetry 5, 183 (1984).

4. Harshaw 8801 dosimeter cards read with a Model 8800 card reader.

5. 60 Watt Sylvania "Lumaline".

6. R.W. Mason, "Thermoluminescence Response of $7 \mathrm{LiF}$ to Ultiaviolet Light", Phys. Med. Biology 16, 303 (1971).

7. Y. S. Horowitz, "Thermoluminescence and Thermoluminescent Dosimetry", page 119, CRC Press, Boca Raton, Florida (1984).

8. P. Spanne, "TL Dosimetry in the $m$ Gray Range", Acta Radiol. 360 (Suppl.), 1 (1979).

9. D. B. Shipler, L. L. Nichols, and L. F. Kocher, "Thermoluminescence from Adhesive Coated Teflor Tape", Health Phys. 22, 195 (1972).

10. F. D. Adams, Thesis, "A Study of the Light Sensitivity of 0.13 mm Thick LiF-Tefion TLD Disks", University of North Carolina; F. D. Adams, D. J. Crawford-Brown, J. E. Watson, M. J. Symons, and P.E. Hamrick, Health Physics Society Arinulal Meeting Report, CONF890619-9, available from NTIS, PC A02/MF A01 - OSTI; GPO Dep. (1989).

11. E. W. Bradley, "Study on the Effects of Room Lighting in Harshaw 8801 (7776-1141) TLD Cards" (unpublished)

12. B. Ben-Shachar and $Y$. Laichter, "The Intrinsic Sensitivity of $\mathrm{LiF}, \mathrm{CaF}_{2}: \mathrm{Dy}$, and $\mathrm{CaF}_{2}: \mathrm{Tm}$ Crystals Exposed to U.V. Radiation and Their Photo-Transferred Luminescence," Proceedings Israel Health Physics Soc. (1987), Report \# INIS-mf-10946; CO.JF-8704181, available from NTIS, PC A04/MF A01

13. B. Ben-Shachar, "Ultraviolet Sensitivity and PhotoTransferred Thermoluminescence of the Harshaw and Panasonic Used TLD's - A Comparison," Appl. Radiation Isot. 40, 687 (1989). 

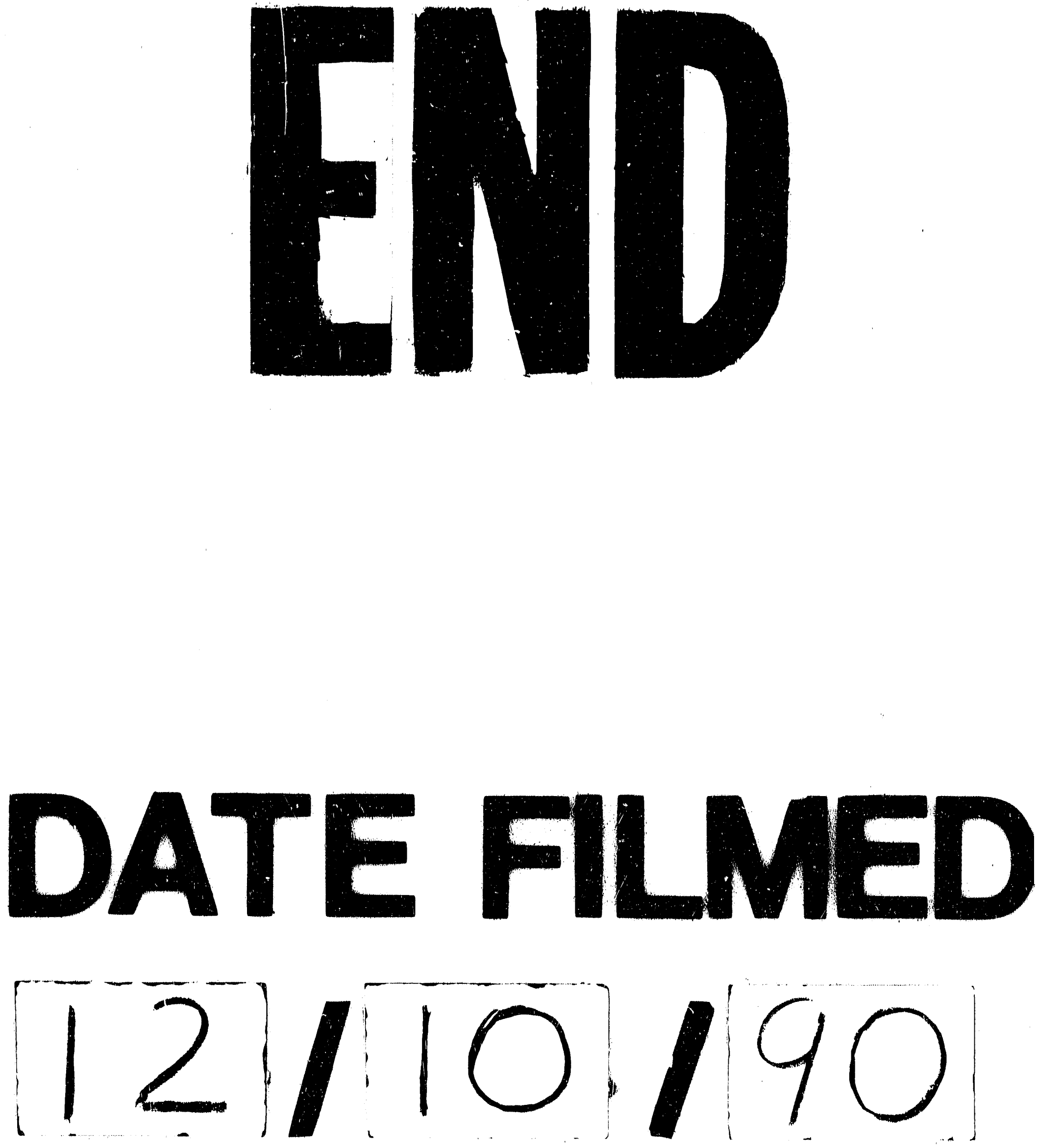


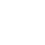

